\title{
More evidence for a planetary wave link with midlatitude $E$ region coherent backscatter and sporadic $E$ layers
}

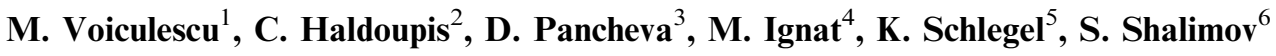 \\ ${ }^{1}$ Physics Department, University of Galati, Galati, Romania \\ ${ }^{2}$ Physics Department, University of Crete, Iraklion, Crete, Greece \\ 3 The Department of Physics, University of Wales, Aberystwyth, Wales, UK \\ ${ }^{4}$ Physics Department, University of Iasi, Iasi, Romania \\ ${ }_{6}^{5}$ Max-Planck Institut fur Aeronomie, Katlenburg-Lindau, Germany \\ ${ }^{6}$ Institute of Physics of the Earth, Moscow, Russia
}

Received: 25 February 2000 / Revised: 26 May 2000 / Accepted: 26 May 2000

\begin{abstract}
Measurements of midlatitude $E$ region coherent backscatter obtained during four summers with SESCAT, a $50 \mathrm{MHz}$ Doppler system operating in Crete, Greece, and concurrent ionosonde recordings from the same ionospheric volume obtained with a CADI for one of these summers, are used to analyse the long-term variability in echo and $E_{s}$ occurrence. Echo and $E_{s}$ layer occurrences, computed in percent of time over a $12-\mathrm{h}$ nighttime interval, take the form of time sequences. Linear power spectrum analysis shows that there are dominant spectral peaks in the range of 2-9 days, the most commonly observed periods appearing in two preferential bands, of 2-3 days and 4-7 days. No connection with geomagnetic activity was found. The characteristics of these periodicities compare well with similar properties of planetary waves, which suggests the possibility that planetary waves are responsible for the observed long-term periodicities. These findings indicate also a likely close relation between planetary wave (PW) activity and the well known but not well understood seasonal $E_{s}$ dependence. To test the PW postulation, we used simultaneous neutral wind data from the mesopause region around $95 \mathrm{~km}$, measured from Collm, Germany. Direct comparison of the long-term periodicities in echo and $E_{s}$ layer occurrence with those in the neutral wind show some reasonable agreement. This new evidence, although not fully conclusive, is the first direct indication in favour of a planetary wave role on the unstable midlatitude $E$ region ionosphere. Our results suggest that planetary waves observation is a viable option and a new element into the physics of midlatitude $E_{s}$ layers that needs to be considered and investigated.
\end{abstract}

Key words: Ionosphere (ionosphere irregularities; midlatitude ionosphere) - Meteorology and atmospheric dynamics (waves and tides)

Correspondence to: K. Schlegel

\section{Introduction}

Recent studies of the unstable midlatitude $E$ region ionosphere suggested that planetary waves may play a role in coherent backscatter occurrence (Tsunoda et al., 1998; Voiculescu et al., 1999) and the formation of strong sporadic $E$ layers (Voiculescu et al., 1999; Shalimov et al., 1999). These studies are the latest to report large-period wavelike effects on midlatitude ionospheric plasma processes most likely caused by neutral atmospheric oscillations of global scale, which are known to exist in the mesosphere and lower thermosphere (MLT). In another study, Zhou (1998) reported a strong two-day modulation in electron density concentration, observed by the Arecibo incoherent scatter radar near the mesopause, which was attributed to the passage of a quasi-2-day planetary wave. In earlier investigations, long-term periodicities in $D, E$, and $F$ region ionisation in the middle- and lowlatitude ionosphere were also measured and attributed to planetary waves (Pancheva et al., 1991, 1994; Chen, 1992; Laštovicka et al., 1994; Apostolov et al., 1995; Fraser, 1977).

The interest in the study of midlatitude $E$ region coherent backscatter phenomena, which exist in close connection with $E_{s}$ layers, has grown remarkably in recent years (e.g. see Haldoupis et al., 1997; Hysell and Burcham, 2000, and references therein). The coherent echoes observed with HF and VHF radars are caused by short-scale field-aligned plasma irregularities. These are generated primarily by the gradient drift instability and nonlinear plasma wave interactions, with the free energy coming from $E_{s}$-related density gradients, ambient dynamo electric fields, localised polarisation electric fields and possibly strong shears in neutral wind (e.g. Riggin et al., 1986; Haldoupis et al., 1997; Kagan and Kelley, 1998). The research in midlatitude backscatter has focused so far on a variety of topics that include the investigation of morphological features, the relation to $E_{S}$ layers, the Doppler spectrum properties, the insta- 
bility mechanisms, the electrodynamics of the plasma, the generation of large polarisation electric fields, and the effects of neutral atmospheric motions, particularly the role played by gravity waves. The possible relationship with planetary waves is the latest topic added to the list.

Planetary waves (PW) are global scale, quasi-periodic oscillations in temperature, wind, density and pressure with periods near 2, 5, 10 and 16 days, which affect the atmospheric dynamics in the region between 80 and $150 \mathrm{~km}$ (e.g. see Forbes, 1994). They are either stationary, being fixed to the Earth, or travelling waves, mostly propagating zonally westward (Forbes, 1996). Although stationary PW are normally excluded above $60 \mathrm{~km}$, travelling waves with periods of 2-16 days are present routinely in the $E$ region ionosphere, especially during summer (Vincent, 1990; Jacobi et al., 1998). For example, the long-term oscillations in the meteor region wind found in radar observations are normally interpreted as signatures of travelling planetary wave motions (e.g. Müller and Nelson, 1978; Manson et al., 1987; Meek et al., 1996; Jacobi et al., 1998). Also, the existence of PW energy in the MLT region has been confirmed by incoherent scatter radars (e.g. Deng et al., 1997) and space-borne sensors (Rodgers and Prata, 1981; Wu et al., 1993, 1996; Ward et al., 1996).

The recent evidence presented by Tsunoda et al. (1998) and Voiculescu et al. (1999), about a possible link between backscatter occurrence and travelling planetary waves, is quite intriguing and opens a new dimension in the research of the unstable midlatitude $E$ region ionosphere and its interaction with the neutral atmosphere. In particular, the results reported by Voiculescu et al. (1999), which suggested that PW may contribute in the formation of strong sporadic E layers, introduced a new option into the long-term research of sporadic $E$ layer phenomena. Given the close dependence of midlatitude backscatter to strong $E_{s}$ (e.g. see Hussey et al., 1998), a physical understanding of the relation between $E_{s}$ and PW could also help explain the long-term periodicities seen in backscatter occurrence. A first step in this direction was reported by Shalimov et al. (1999), who tried to formulate precisely the PW role on strong $E_{s}$ production. They presented a simplified model based on the notion of metallic ion-converging properties of horizontal wind shears associated with regions of positive vorticity within a zonally propagating planetary wave.

Obviously, the postulation of PW effects on the midlatitude $E$ region ionosphere is an attractive new element into the physics of the relevant phenomena, which demands for additional research, both experimental and theoretical. In particular, it is important that the existence of this PW relationship is substantiated further by means of additional experimental evidence. The present study aims to serve this purpose by supplementing with more details, observations and discussions the material reported in a research letter by Voiculescu et al. (1999). In addition, we provide for first time some direct evidence in favour of a PW role by comparing the long-term periodicities in radar backscatter and ionosonde sporadic $E$ layer observations with those in concurrent neutral wind measurements at the lower $E$ region (near $95 \mathrm{~km}$ ) made in the European sector.

\section{Long-term periodicities in midlatitude backscatter and $E_{s}$ occurrence}

The observations to be presented here were obtained with SESCAT (Sporadic E SCATter experiment). This is a continuous-wave (CW) $50.52 \mathrm{MHz}$ bistatic Doppler radio experiment positioned at midlatitudes, on the island of Crete, Greece. The transmitter and receiver are separated by about $120 \mathrm{~km}$ and have their antenna arrays beaming northward and intersecting at $E$ region altitudes over an ionospheric area of about $15 \mathrm{~km}$ in longitude and $30 \mathrm{~km}$ in latitude, at about $36.7^{\circ} \mathrm{N}$ and $24.7^{\circ} \mathrm{E}$ geographic and $30.8^{\circ}$ invariant geomagnetic latitude $\left(L\right.$ shell value $=1.35$, magnetic dip $I=52.5^{\circ}$, magnetic declination $D=2.5^{\circ}$ ). The experiment was designed specifically for high-resolution measurements of coherent backscatter from field-aligned irregularities, which are believed to be generated in the presence of strong sporadic $E$ layers under the action of the gradient drift instability (e.g. see Riggin et al., 1986). For more details about the SESCAT experiment see Haldoupis and Schlegel (1993).

SESCAT can observe high-resolution Doppler spectra of the backscattered signal on a continuous basis. Because of the small operating costs, it has been run continuously for long periods of time collecting vast amounts of data which are especially suited for studying long-term variations and periodicities, a subject undertaken with the present study. The motivation was the general observation that midlatitude backscatter occurrence seemed to obey a well-defined and repeatable pattern. Very active nights with 30 to $50 \%$ in echo occurrence were followed by quiet nights of 0 to $5 \%$ echo activity, which suggested a long-term quasiperiodic behaviour of the phenomenon. This pattern can be recognised in Fig. 1 which shows in the lower panel a heavily averaged Doppler spectrogram and in the upper panel the corresponding mean Doppler velocity, for the interval from 8 to 31 July, 1995. In this plot the backscatter activity is identified with nighttime periods when a Doppler broadening is seen in the spectrogram often accompanied by an increase in the mean Doppler velocity; the rest of the apparent activity there is mainly due to meteor echoes, and aircraft reflections through antenna sidelobes.

As mentioned in the introduction, the present work supplements the results of the research letter by Voiculescu et al. (1999) referred to in the following as paper A. Although most of the results shown here correspond to additional data not considered in the analysis of paper A, some repetition was unavoidable, done for the sake of completeness.

In the search for long-term periodicities we were restricted to deal with summer nighttime periods only, because, as shown statistically by Haldoupis and Schlegel, (1996), midlatitude backscatter occurs overwhelmingly 


\section{SESCAT Doppler Spectra: Long Period Echo Occurrence Start Time 08/07/95, 00:00 UT End Time : 30/07/95, 24:00 UT}

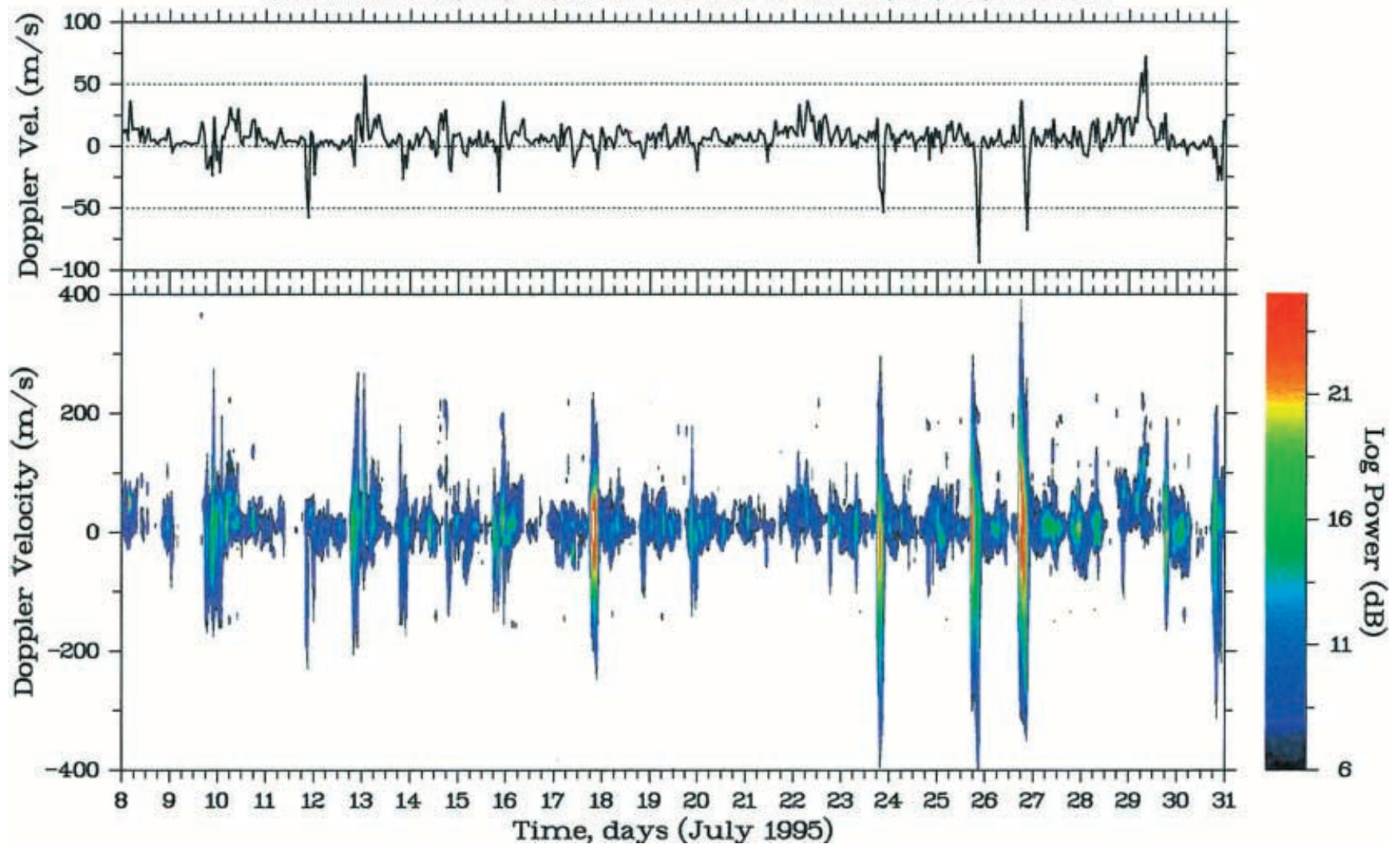

Fig. 1. A heavily averaged Doppler velocity-time-intensity spectrogram showing long-term periodicities in $50 \mathrm{MHz}$ backscatter occurrence, as observed by SESCAT from 8 to 31 July, 1995. Echoes occur during times of Doppler broadening often followed by enhancements in the mean Doppler velocity shown in the upper panel. The continuum is due to meteor scatter and aeroplane reflections in the dark hours during summer e.g. see also Tanaka and Venkateswaran (1982) and Yamamoto et al. (1992). Consequently, only the daily 12-h interval from 1800 to $0600 \mathrm{UT}$ (UT $=\mathrm{LT}+1.6 \mathrm{~h}$ ) has been considered in the analysis, which thereafter is referred to as "day". In line with the procedure adopted in paper A, observations were included only if echoes had signal-tonoise ratios (snr) greater than $2 \mathrm{~dB}$, spectrum widths larger than $20 \mathrm{~m} / \mathrm{s}$, and lifetimes longer than $2 \mathrm{~min}$, which helped avoid meteor scatter. In this work we deal only with changes in echo occurrence, whereas variations in echo intensity and in Doppler spectrum were left for a future study. An algorithm was used to measure the total duration of scatter per day in minutes and form time series for the echo occurrences expressed as percentage of the 12-h day. The analysed time intervals are listed in Table 1 for all the summers of continuous SESCAT operation. The radar operation gaps for the intervals in Table 1 represented, on average, less than about $3 \%$ of the time.

Figure 2 displays the time sequence of echo occurrence and the corresponding power spectrum for the period from June 30 to August 25, 1993. This figure is similar to Fig. 1 of paper A for the summer of 1995 . It shows a pronounced daily variability in backscatter with periods ranging from two to several days, as evidenced
Table 1. Intervals of SESCAT observations

\begin{tabular}{ll}
\hline Year & Analysed interval \\
\hline 1993 & $29.06-30.09$ \\
1995 & $19.06-31.08$ \\
1996 & $13.06-3.10$ \\
1997 & $23.06-18.08$
\end{tabular}

from the normalised Fourier power spectrum in the lower panel; the spectrum shows two dominant bands of periods, that is, from 2 to about 3 days and 4 to 7 days. Also, a careful inspection of the time series in Fig. 2, shows that prevailing periods change as time progresses from June to September, so that intervals of 10 to 20 days characterised by a certain period, are followed by intervals dominated by a different period. This was confirmed by spectrally analysing sequential sub-intervals in order to determine the dominant period in each of them, which then, was applied to fit the occurrence sequence with a sinusoid of a fixed period but of adjustable phase and of arbitrary amplitude.

The sinusoidal fittings for sequential subintervals of the 1993 data are summarized in Fig. 3, which is similar to Fig. 2 in paper A for 1995, and Fig. 6 for 1996, which is to be discussed later. The results of the 
Backscatter occurrence power spectrum

$30 / 06 / 93-25 / 08 / 93$

$\therefore$
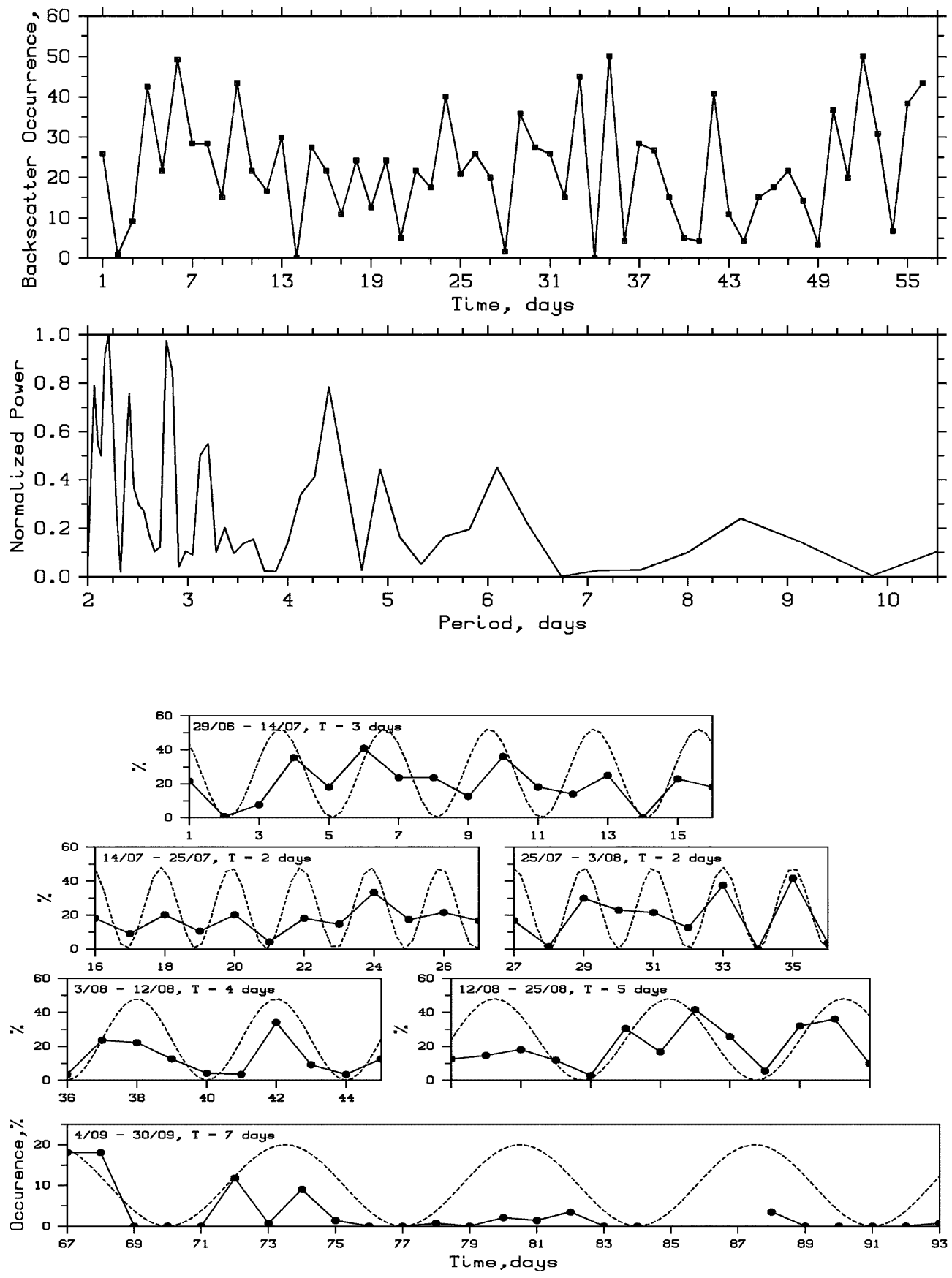

Fig. 2. Time sequence of backscatter occurrence (upper panel) and the corresponding self-normalized power spectrum for the time interval from June 30 to August 25, when SESCAT operated continuously
Fig. 3. Sequential time series (solid line) and fitted sinusoids (dashed lines) with dominant periods for the daily backscatter occurrence during the summer of 1993, from June 29 to the end of September. The small occurrences observed during September are significant analysis for the entire data set have identified a number of dominant periods for an equal number of corresponding subintervals, which are all listed in Table 2. Except for the case of a rather long period of 9 days in 1997, the rest can be grouped into two bands, that is the 2 to 3 days and the 4 to 7 days band. Although these values are approximate, they do emphasise the existence of a repeatable pattern of a few days-long periodicities in backscatter occurrence. Another interesting aspect that emerges from Table 2 on the average is an apparent decrease, followed by an increase of the period as we move from the beginning to the end of the summer. This trend is better emphasised with Fig. 4, which is a summary plot for all four summers showing the appearance of the observed dominant periodicities as a function of day in summer. Note that the few gaps in the 1996 sequence of backscatter occurrence were interpolated based on the sporadic $E$ sequence which was continuous (see Fig. 5) for the entire summer.

Besides the SESCAT observations, ionosonde measurements were also available concurrently for one of the 
Table 2. Predominant periods of wave-like variations in echo occurrence

\begin{tabular}{ccl}
\hline Year & Time interval & $T$ (days) \\
\hline 1993 & $29.06-14.07$ & 3.0 \\
& $14.07-3.08$ & 2.0 \\
& $3.08-12.08$ & 4.0 \\
& $12.08-25.08$ & 5.0 \\
& $4.09-30.09$ & 7.0 \\
1995 & $19.06-1.07$ & 4.0 \\
& $2.07-13.07$ & 2.5 \\
& $14.07-22.07$ & 2.0 \\
& $23.07-7.08$ & 4.5 \\
& $1.08-29.08$ & 6.5 \\
1996 & $23.06-2.07$ & 6.0 \\
& $5.07-19.07$ & 2.0 \\
& $19.07-8.08$ & 3.0 \\
& $13.08-4.09$ & 6.0 \\
& $4.09-3.10$ & 6.5 \\
1997 & $23.06-6.07$ & 2.5 \\
& $6.07-26.07$ & 9.0 \\
& $27.07-18.08$ & 5.0 \\
\hline
\end{tabular}
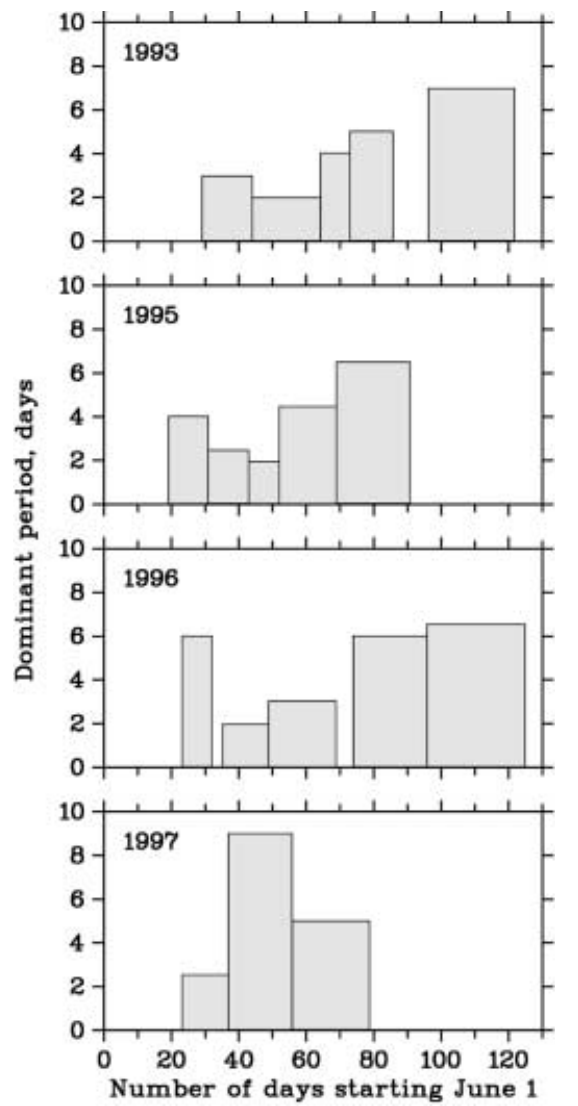

Fig. 4. Plots summarising the dominant periods and their change with time during summer from June 1 to September 30, as observed by SESCAT during its operation in the summer of 1993, 1995, 1996 and 1997

summers included in this study. From June 23 to October 3, 1996, a Canadian Advanced Digital Ionosonde (CADI) was operating in the island of Milos, nearly below SESCAT viewing region, recording ionograms every 2 min during the night from 18:00 to 06:00 hours LT. Given the close relationship that exists between coherent backscatter and strong sporadic $E$ layers (e.g. see Hussey et al., 1998), an effort was made to investigate whether the long period variations observed in backscatter were also present in the occurrence of intense sporadic $E$ layers. To be consistent with the methodology applied to our previous analysis, the total duration of strong sporadic $E$ layers with layer top-frequencies $f_{t} E_{s}>5 \mathrm{MHz}$ was measured in minutes and the $E_{s}$ occurrence was computed as percentage of time. Actually, the analysis described here was also presented in paper A, but there only part of the available data were used, that is, the interval from July 7 to August 27, 1996 when operation gaps in SESCAT data were minimal.

Figure 5 shows the time sequences for strong $E_{s}$ and $50 \mathrm{MHz}$ echo occurrences, superimposed on the same plot for direct comparison. As anticipated, the two sequences compare quite well, which is a confirmation of the close relationship that exists between the two phenomena. Of course, what is of interest here is not so much the good correlation between occurrences, but the important implication that the same long period variations shown to exist in midlatitude backscatter are also present in the occurrence of strong $E_{S}$ as well. This conclusion is reinforced by Fig. 6, which was produced in the same way as Fig. 3, that is, by using a subinterval power spectrum analysis to find the dominant period and then fit this sinusoid to the time series of that interval by adjusting its phase. Although we used only $E_{s}$ occurrence sequences to find the dominant periods, the sequences of echo occurrence are also superimposed in Fig. 6 for comparison. The good agreement between the sinusoids and the measured time series shows that both, strong $E_{s}$ and $50 \mathrm{MHz}$ echo occurrences are characterised by the same long-term variability with periods in the range from two to several days. We believe that this is an important finding, with respect to the observed properties of midlatitude sporadic $E$ layers, not reported before in the open literature.

To investigate if there is a relation with similar longterm periodicities in geomagnetic activity, the time series of the daily averaged $K_{p}$ index, corresponding to all four SESCAT data intervals, were formed and correlated with the echo occurrences. The results of this comparison indicated no correlation between the two phenomena. As an example, Fig. 7 shows the time series for echo occurrence of $K_{p}$ for the summer of 1995 and the corresponding correlation scatter plot, both showing a rather poor relation between the two variations. The same picture applies for the other summers as well. Specifically, the computed linear correlation coefficients $(r)$ were found to be rather small and mostly negative; $r$-values were equal to $-0.12,-0.04,0.26$ and -0.16 for the summers of 93, 95, 96 and 97, respectively. This lack of correlation is actually anticipated because past studies indicated no relation between midlatitude coherent backscatter and magnetic activity, e.g. see Haldoupis and Schlegel, (1996), and also between magnetic activity and sporadic $E$ layer occurrence (e.g. see Whitehead, 1989 and references therein). 
Backscatter and Es occurence: 23/06/96 - 3/10/96

Es top freq $>5 \mathrm{MHz}$

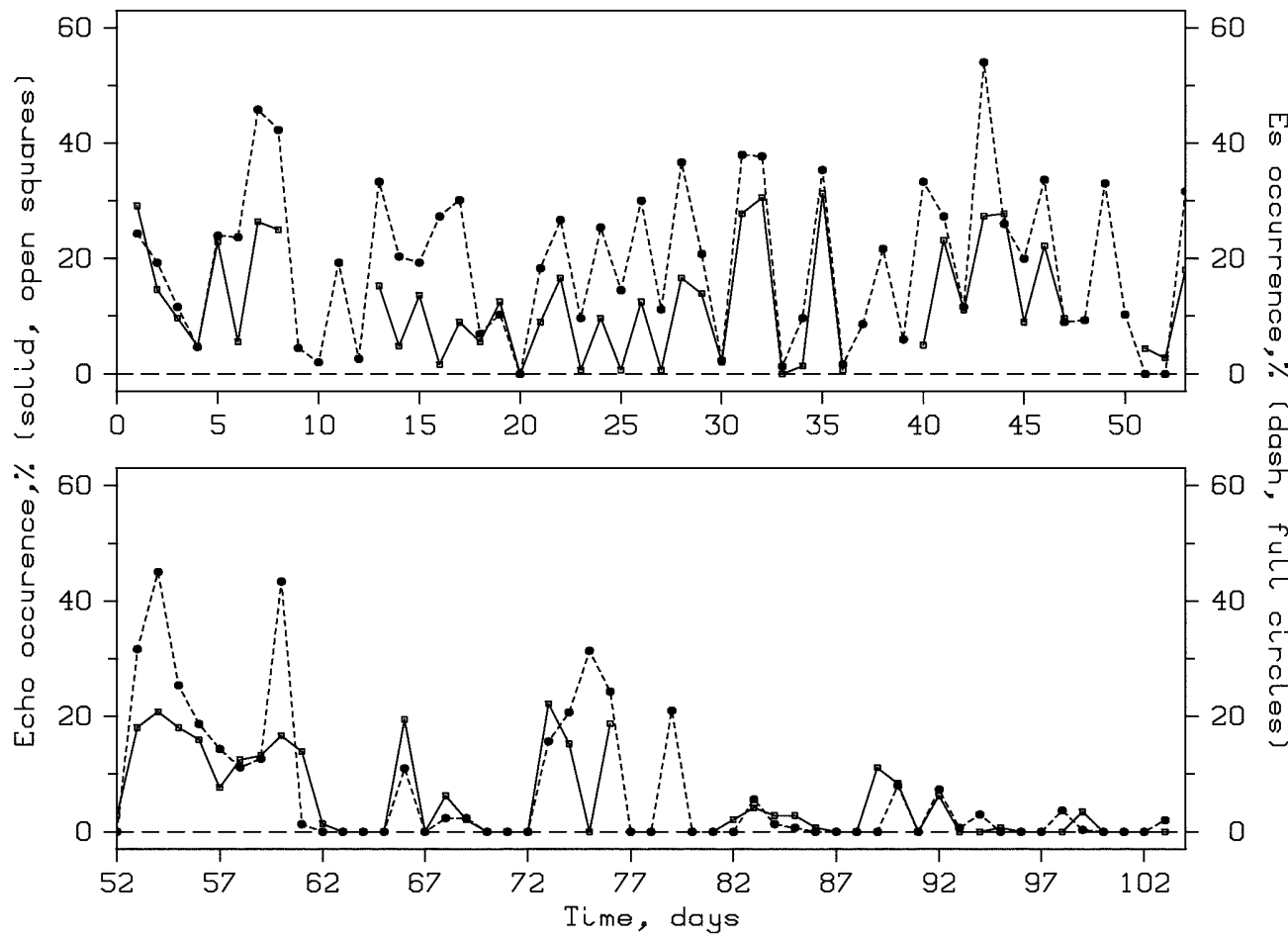

Periodic variations in Echo and Es occurrence Es top freq $>5 \mathrm{MHz}$
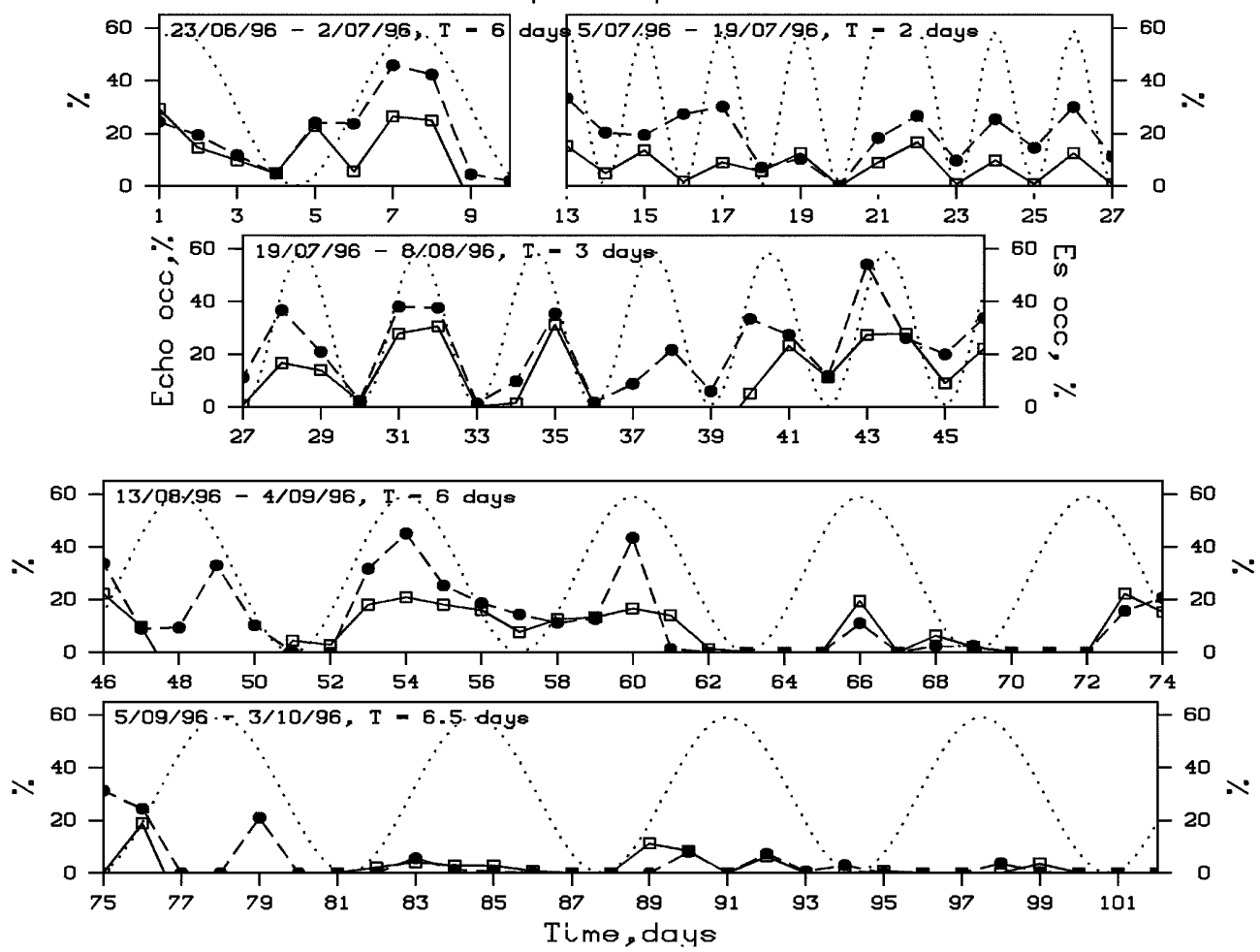

Fig. 5. Time sequences of $50 \mathrm{MHz}$ echo occurrence observed by SESCAT (solid lines) and strong sporadic $E$ layer occurrence observed by CADI continuously from June 23 to October 3, 1996. Both time sequences correlate well as a result of the close relationship that exists between the two phenomena. The long-term periodicities in both sequences have periods that compare well with planetary wave periods

Fig. 6. Same as Fig. 3 but for the dominant periodicities observed in the ionosonde (CADI) data during the summer of 1996. Again, the small occurrences during September are significant

\section{A possible relation with planetary waves}

The observed long-term periodicities in backscatter and $E_{s}$ occurrences prompted Voiculescu et al. (1999) to suggest a possible link with planetary waves. This option was inferred indirectly from comparisons with published results on PW morphological properties and other observational characteristics. In this section we present 

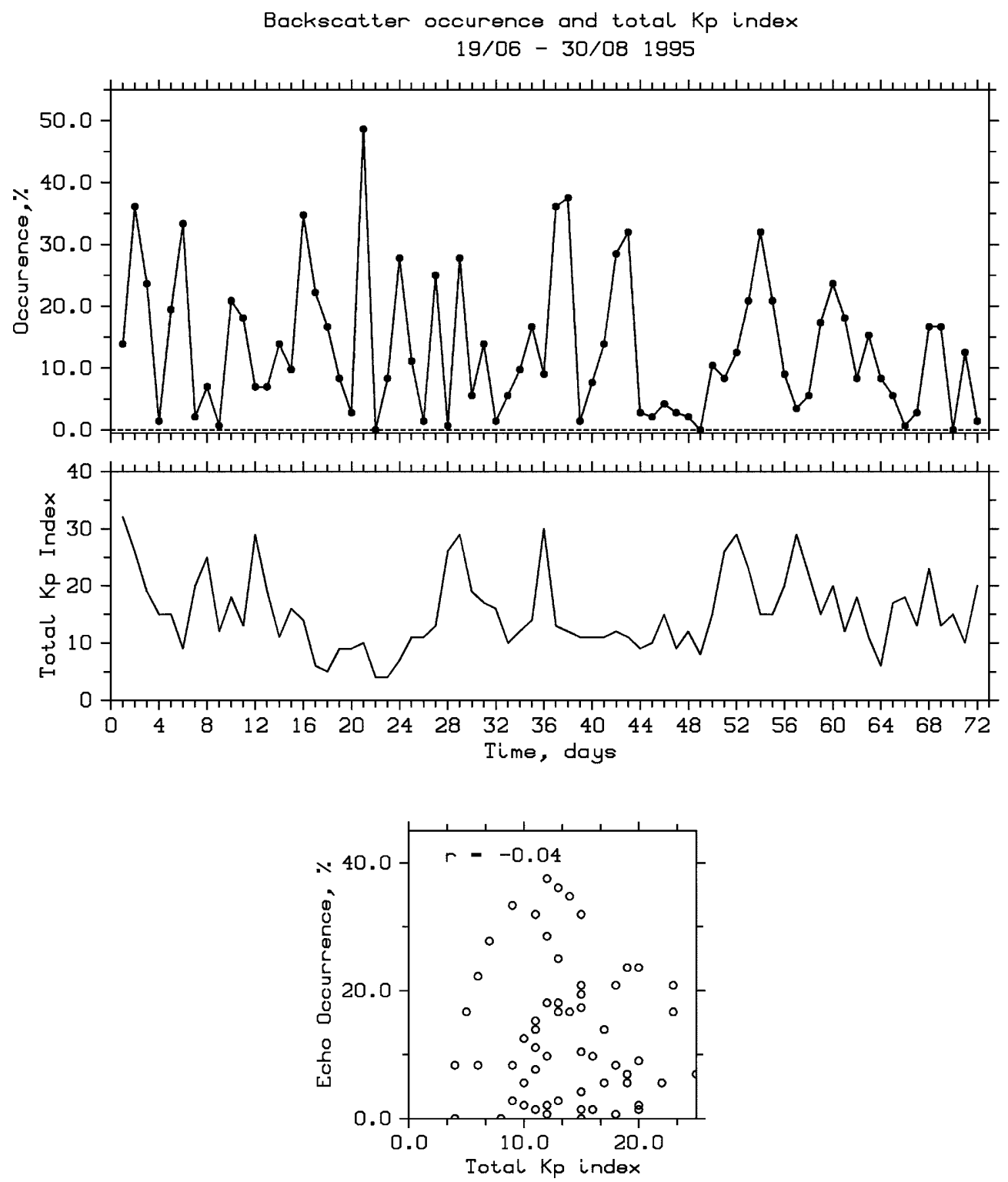

Fig. 7. Comparison between the echo occurrence and the corresponding daily $K p$ time sequences during summer 1995. Shown also in the bottom panel is the scatter plot correlating the two time sequences. As seen, there is no correlation to geomagnetic activity. The same is also true for the rest of the summers considered in the analysis, that is 1993 , 1996 and 1997 more details about how basic PW characteristics compare to our observations.

Although PW activity exhibits interannual variations with respect to the dominant periods, wave amplitudes, duration, and seasonal occurrence (e.g. see Meek et al., 1996; Jacobi et al., 1998), they seem to have some wellestablished properties. First of all, the PW spectrum has two components, the stationary and the travelling modes, the last one having typical durations of 15-30 days (Vincent, 1990; Jacobi et al., 1998). Contrary to the stationary mode, travelling PW are less vulnerable to reflection and absorption by a shear in the mean wind which makes them potentially more important in the lower thermosphere (e.g. see Meek et al., 1996; Forbes, 1994; Salby, 1981, 1984), whereas their existence in the lower $E$ region has been confirmed by several observations (e.g. Williams and Avery, 1992; Meek et al., 1996; Müller and Nelson, 1978; Manson et al., 1987, among others). Travelling PW are considered as evanescent solutions of the Laplace tidal equation for an isother- mal, non-disipative atmosphere. They are identified as normal rotational Rossby modes, propagating westward with phase velocities in the range from 5 to $40 \mathrm{~m} / \mathrm{s}$ (Forbes, 1996; Holton, 1982). At times when stationary wave activity is reduced, as it is often the case in summer (Charney and Drazin, 1961; Holton, 1982), travelling waves, known as the "quasi-2 day", "quasi-5 day", and "quasi-10 day" period waves, dominate the PW spectrum.

The "quasi-2 day wave" (QTDW), with periods of 1.8-2.5 days, is a manifestation of the mixed Rossbygravity $(3,0)$ mode. These waves last from 10 to 30 days and can reach amplitudes from about 15 to $40 \mathrm{~m} / \mathrm{s}$, which makes them the strongest signal in the PW time scale range (Jacobi et al., 1998). Although the QTDW might appear once, twice or not at all during a season (Meek et al., 1996), it is the most regular travelling PW in summer. The QTDW energy peaks in summer after solstice and drops sharply after middle of August moving towards a minimum near equinox, and reaching 
a second, much weaker, peak in winter. (e.g. see Harris, 1994; Müller and Nelson, 1978; Clark et al., 1994; Meek et al., 1996). As pointed out in paper A, the QTDW properties are consistent with the variations in backscatter and sporadic $E$ layer occurrences.

Periods of 4-7 days relate to the "quasi-5-day wave", identified as Rossby $(1,1)$ mode. Although its activity can be enhanced during the entire summer, the general pattern is characterised by maxima in early summer (May) and late summer (August/September) (Manson et al., 1987; Jacobi et al., 1998) with quasi-two day waves dominating in between. Interestingly, the change of the prevailing periods with time, seen in most of our data (e.g. see Fig. 4), is in fact a general trend for the maximum of the PW activity. Our data displays larger period (4-6 days) variations in early summer, succeeded by smaller period (2-3 days) ones around and after solstice, which then are followed by larger period (5 to 6 days) variations in late summer. The only observed periodicity departing from this pattern was the 9-day oscillation found in the July 1997 backscatter. This single periodicity could be the signature of a "quasi-10day" wave, which, although it's maximum occurs mostly in early spring or late autumn (Manson et al., 1981; Jacobi et al., 1998), it also may dominate, occasionally, the PW spectrum for part of the summer (Jacobi et al., 1998).

The PW energy could relate somehow to the generation of midlatitude echoes. For example, echo occurrences are observed to be less than $15 \%$ for large period variations whereas high echo occurrences of 30 to $50 \%$ are identified with time intervals dominated by periods between 2 and 5 days, maximum. This seems to be in line with PW observations suggesting that shorter period waves have larger amplitudes, for example amplitudes of 15-30 m/s characterise the quasi 2-day wave, as compared to $5-10 \mathrm{~m} / \mathrm{s}$ for the quasi 10-day wave (Jacobi et al., 1998).

Another indirect evidence in support of a possible $\mathrm{PW}$ role for strong $E_{s}$ layer generation is the similitude between the seasonal morphologies of the two phenomena. As has been known for many years (e.g., Whitehead, 1989), strong midlatitude $E_{s}$ layers occur overwhelmingly during summer having a pronounced maximum after solstice. This observation, which cannot be explained by wind shear theory, constitutes a longstanding problem in $E_{s}$ research. As discussed in paper A, and also by Shalimov et al. (1999), there is a striking resemblance between the PW climatology and seasonal $E_{s}$ dependence which strengthens the possibility of PW effects on strong $E_{s}$ generation and backscatter occurrence. To emphasise this we provide here Fig. 8, reproduced from Shalimov et al. (1999). Figure 8 shows the annual occurrences of midlatitude $E_{s}$ (from Sprenger, 1981) and $50 \mathrm{MHz}$ backscatter (from Haldoupis and Schlegel, 1996), superimposed on the annual variation of the zonal and meridional QTDW mean amplitude, computed from Fig. 1 of Jacobi et al. (1998). As seen, all three seasonal variations are fairly similar.

Based on indirect evidence, we conclude that the characteristics of long-term variations in the observed $E_{s}$ solid : Midlatitude Es, FoEs > $5 \mathrm{MHz}$ (Sprenger, 1981) dash : $50 \mathrm{MHz}$ backscatter (Haldoupis and Schlegel, 1996) triangles: QTDW zonal(open) and merid. (Jacobi et al.,1998)

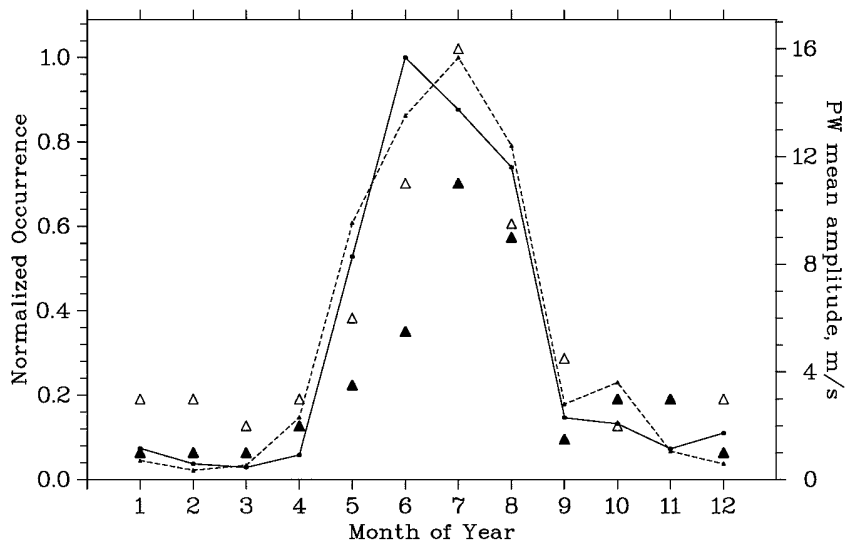

Fig. 8. Comparison of seasonal morphologies between midlatitude sporadic E (solid line), coherent backscatter at $50 \mathrm{MHz}$ (dashed line), and of the quasi-two-day wave zonal and meridional mean wind component (open and solid triangles). Note that these curves are compiled here from independent measurements not necessarily during the same time intervals. As seen, there is good correlation between all seasonal dependences (from Shalimov et al., 1999)

and backscatter occurrences (dominant periods and their changes with time, duration of periodicities, and seasonal characteristics) compare well with corresponding PW properties. Nevertheless, the best evidence in support of a relation between these phenomena can come only from a direct comparison between concurrent data. A first comparison of this type is presented in the following section.

\section{Comparison with simultaneous planetary wave data}

Here, the periodicities found in SESCAT backscatter and CADI $E_{s}$ occurrences are compared directly with concurrent long period wind oscillations observed during the summers of 1995 and 1996 in central Europe. The neutral wind data, which refer to the mesopause region near $95 \mathrm{~km}$ height, were obtained in Collm, Germany $\left(52^{\circ} \mathrm{N}, 15^{\circ} \mathrm{E}\right)$ by using radio wave absorption measurements of ionospherically reflected sky waves of commercial radio transmitters in the LF range. For details about the Collm measurements, the measuring technique, and the data reduction method, see Jacobi et al. (1998). The final wind data analysed in the present study are averaged daily values of the zonal and meridional wind, measured, for summer days, mainly at twilight and at night. The latter is, in a way, advantageous for the present comparison because both our backscatter and $E_{s}$ data resulted from nighttime measurements.

In comparing the ionospheric measurements in Greece with mesopause neutral wind observations from Germany, we are aware of the large distance between the sites, which could introduce spatial discrepancies. These, however, are not expected to be crucial because PW are large-scale atmospheric variations of global 
character having typical horizontal scale lengths of 7000-10 $000 \mathrm{~km}$, that is, much larger than the distance between the sites. More specifically, the difference in longitude between central Crete and Collm corresponds to about $1000 \mathrm{~km}$, thus for a westward propagating PW with a typical phase velocity of $80 \mathrm{~km} / \mathrm{h}$ the resulting time lag is of the order of 12 hours, which is only a fraction of the PW periods. Also, the meridional distance of about $1800 \mathrm{~km}$ between the two locations should not have a serious effect in this comparison because PW occupy larger latitudinal sectors. On the other hand, however, one cannot exclude completely space discrepancies between the two data sets because the PW meridional and zonal components are known to exhibit spatial differences. For example, the QTDW is elliptically polarised, with its meridional component being larger (sometimes by a factor of 2 ) than the zonal one (Clark et al., 1994). Both components have a latitudinal dependence: the meridional component maximises at the equator and decreases with increasing latitude, whereas the zonal component, minimal at the Equator and high latitudes, reaches its maximum at about $30^{\circ} \mathrm{N}$ (Salby, 1981). The situation reverses for the quasi 5-day wave; the zonal component dominates over the meridional one, reaching its maximum at low latitudes (Geisler and Dickinson, 1976; Raghava et al., 1995).

In the present analysis we used simultaneous neutral wind data sequences for the same time intervals when continuous SESCAT backscatter and CADI sporadic $E$ occurrences were measured for 1995 and 1996, respectively. With respect to Collm data, we analysed time series for the zonal (u) and meridional (v) wind components, and the total wind kinetic energy, which is proportional to $\mathrm{u}^{2}+\mathrm{v}^{2}$. The presumption that $\mathrm{PW}$ play a role in the occurrence of backscatter and strong $E_{s}$ layers does not imply necessarily that $\mathrm{PW}$ is the only prerequisite for the generation of $E$-region irregularities. Even if there were no spatial differences, one should not expect an exact coincidence between the ionospheric and the neutral wind long-term periodicities. Therefore, in the analysis we compare period-bands rather than exact periods.

All concurrent data sequences, which are time series of mean daily values, were analysed the same way in order to obtain period-time-intensity (PTI) spectrograms, which then are simply compared one against the other in order to assess qualitatively their degree of resemblance. The spectrograms were obtained by Fourier transforming the first 20-point time series segment to get the amplitude spectrum and then repeating this by sliding the 20-point window along the entire summer interval by one day at a time. This method of dynamic spectral analysis (known also as a short-time Fourier transform) has the disadvantage of not allowing always distinction between a signal representing, say, the sum of two concurrent components with different frequencies from a signal consisting of the same components occurring consecutively within a given time window. In other words, the information cannot be confined always in the time frame it occurs since the short-time
Fourier transform, similarly to the ordinary Fourier transform, also spreads information about the localised features over all frequencies making it impossible to confidently localise these features. Nevertheless, the method is useful in identifying approximately the main periodicities in the signal and how they develop in time, and is more suitable in the search for concurrent periodicities in two independent time sequences, as is in our analysis. Since we are interested in identifying typical PW periodicities, in the analysis we considered periods between the Nyquist period of 2 days and a maximum of 10 days. Each spectrogram presents amplitude spectrum, measured in the same units as the analysed time series.

Figure 9 shows the concurrent spectrograms of strong $E_{S}$ occurrence (bottom plate) measured in Milos and zonal neutral wind measured in Collm (top plate), from June 19 to September 30, 1996. The zonal wind spectrogram was chosen here, because, according to a mechanism presented by Shalimov et al. (1999), which is discussed later, PW could contribute in the formation of strong $E_{S}$ mostly through a horizontal shear in the zonal wind. On average, the two spectrograms compare quite well, in the sense that most of the long-term periodicities seen in $E_{s}$ occurrence are present approximately in the zonal wind as well. The CADI spectrogram shows a 5-day band wave at the beginning of the interval, which also exists in the zonal wind, whereas a 7-8 day periodicity is also present in both PTI plots up to the middle of July. This activity is followed by periodicities in the 2- to 4-day period band existing in both spectrograms throughout July and the first part of August. The second half of the summer interval under analysis is characterised in both time sequences by longer period variations, mostly in the 5- to 7-day band which become rather dominant after about middle of August. In addition, a clear tendency is evident in both PTI plates for the periods to increase as time progresses from mid July to the end of September, when finally a 7- to 8-day periodicity dominates both phenomena. Overall, we can state that there is a good deal of similarity between the prevailing periodicities. This is certainly promising since it is supportive of a $\mathrm{PW}$ role in $E_{s}$ formation, but it cannot be fully conclusive before more comparisons are made.

The situation for the summer of 1995 is resumed in Fig. 10, where the spectrograms are shown of SESCAT echo occurrence (bottom) and neutral wind kinetic energy (top). Here we present and compare the wind kinetic energy spectrogram, instead of the individual wind component ones, because it is representative of the total PW intensity and combines the periodicities in both the zonal and meridional components thus providing an integrated and more general picture. Again, the comparison here focuses on broader period bands rather than the exact periods. As seen, there is some general agreement between the two PTI plots with the variations in echo occurrence comparable in terms of dominant period bands and lifetimes with the PW periodicities that characterise the neutral wind. From the beginning of the time interval till about middle of 

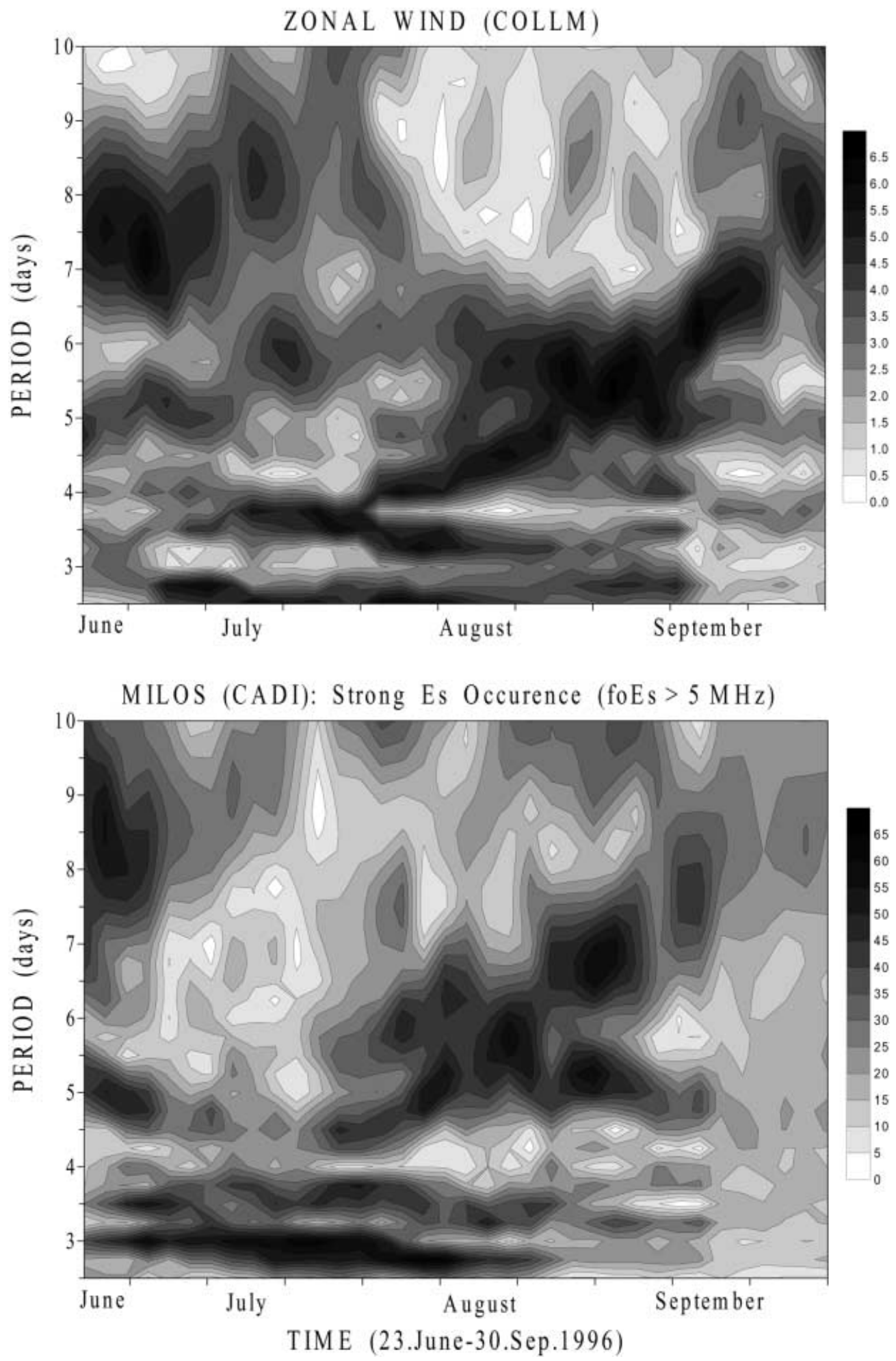

Fig. 9. Simultaneous spectrograms (period-time-intensity), for the period from June 23 to September 30, 1996, of strong sporadic $E$ layer occurrence (bottom panel) observed with CADI in central Aegean, Greece, and of the zonal neutral wind component (top panel) at about $95 \mathrm{~km}$ height measured from Collm, Germany
July both spectrograms are dominated by short period variations in the 2- to 5-day band. They are followed by a longer-period activity, in the 4- to 7-day band, which dominates both PTI plates for nearly one month, from about middle July until the middle of August. Also seen in the neutral wind energy, is an 8- to 9-day periodicity, which is only partially present in the backscatter sequence. Finally, the end of the summer interval under examination is occupied mostly by a longer period variation, in the 7- to 10-day band, which is present in both spectrograms, although not exactly coincident in time.

In brief, we conclude that a reasonable general agreement is present between the PW periodicities in neutral wind and the concurrent variability in backscatter occurrence, but this agreement is certainly not exact. The latter is, however, to be expected given the shortcomings of our analysis as well as the diversity 

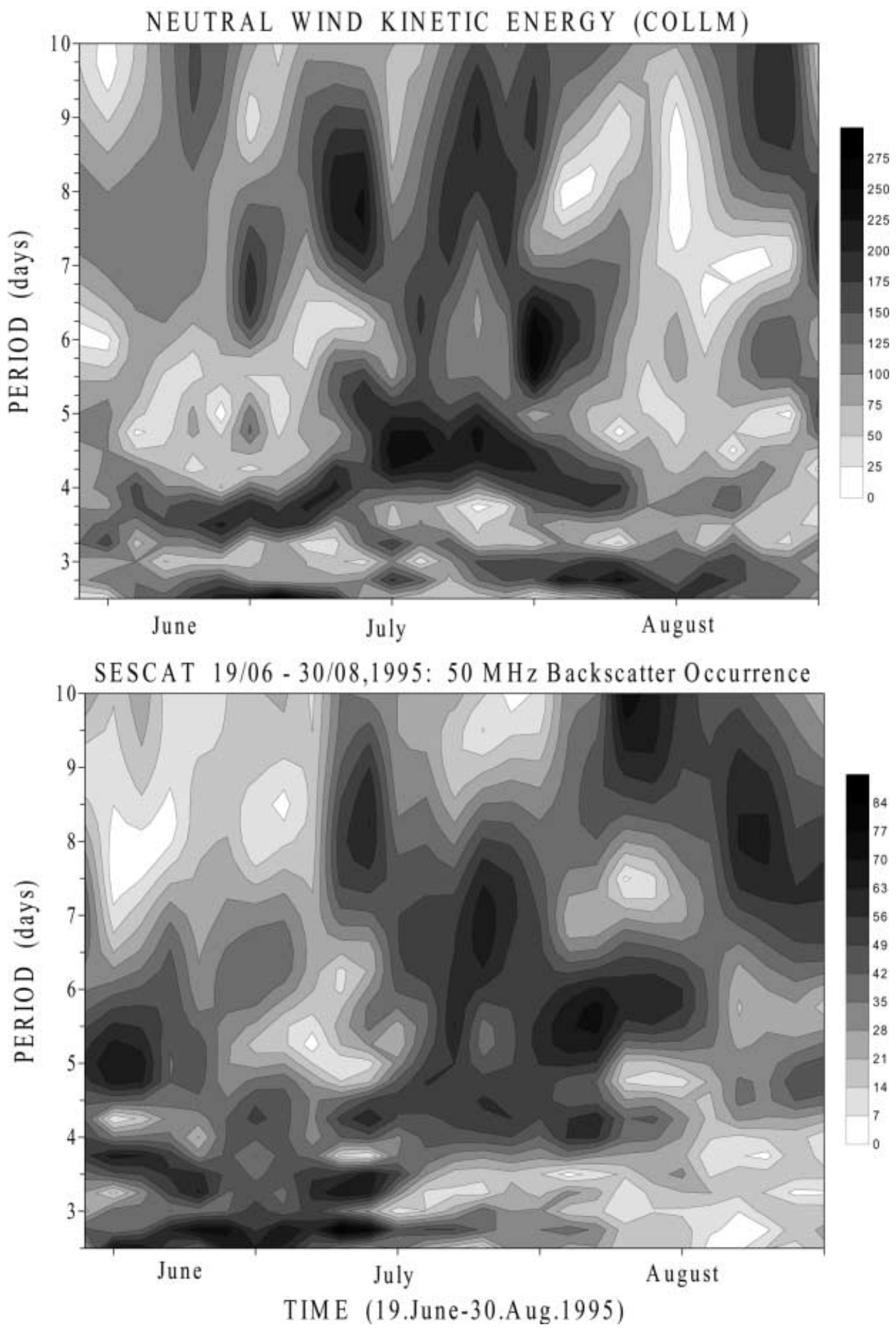

Fig. 10. Simultaneous spectrograms (period-time-intensity) for the period from June 19 to August 30, 1995, of coherent backscatter occurrence (bottom panel) observed by SESCAT from the $E$ region over the central Aegean, Greece, and of the total kinetic energy in the neutral wind (top panel) near $95 \mathrm{~km}$ height measured from Collm, Germany and complexity of the processes which presumably transfer energy from the large-scale PW into the generation of short-scale $E$ region irregularities that scatter the radio waves.

\section{Discussion}

We have presented for first time some direct evidence in favour of a relationship between planetary wave period- icities in the neutral wind and the long-term variations in occurrence of midlatitude VHF backscatter and sporadic $E$ layers. Although this evidence cannot be fully conclusive, it is certainly of importance and emphasises the need for a comprehensive interpretation and a physical understanding of the relation between PW and sporadic $E$ layer phenomena.

Seemingly, the problem has a dual character; that is, we need to understand the PW relation with both, sporadic $E$ and backscatter. The most fundamental 
aspect, however, relates to the role played by PW in the formation of strong $E_{s}$ layers, since midlatitude coherent echoes are observed in close connection with strong sporadic $E$ layers. The latter are resumed to provide the vertical density gradients that help destabilise the plasma via the gradient drift instability (e.g. see Riggin et al., 1986). As a matter of fact, the presence of a strong $E_{s}$ is considered to be a necessary, although not always sufficient, condition for the generation of the scattering irregularities (e.g. see results of Hussey et al., 1998). Consequently, a mechanism explaining the relation between PW and strong $E_{s}$ implies also an indirect PW role for the backscatter occurrence as well.

A mechanism along these lines was proposed recently by Shalimov et al., (1999) in an effort to explain how $\mathrm{PW}$ contribute in the formation of strong $E_{s}$, which, if valid, could account for the periodicities in backscatter as well. On the other hand, the generation of midlatitude irregularities is a complex process which requires, in addition to the density gradients associated with strong $E_{s}$, enhanced electric fields and/or strong neutral winds, as discussed for example recently by Kagan and Kelley (1998). In this respect, another process, which assumes a direct PW action on the driving terms of the gradientdrift instability maybe also applicable. For instance, Tsunoda et al. (1998) proposed a PW-driven dynamo in the ionosphere that can enhance electric fields, which in turn would produce field-aligned irregularities (FAI) and control the backscatter occurrence. The disadvantage of this process, however is that it cannot account for the long-term variability in $E_{s}$, seen in the CADI data to occur in phase with the $50 \mathrm{MHz}$ echoes.

The mechanism by Shalimov et al. (1999) is simple and, because of this, quite attractive. In this process, the $E$ region metallic ion plasma is forced to converge horizontally and accumulate inside areas of positive vorticity setup by cyclonic neutral wind shears within a planetary wave. In a barotropic atmosphere under geostrophic balance, PW are characterised by large cyclonic and anticyclonic vortices propagating westward (Holton, 1982; Volland, 1988). Shalimov et al. (1999) argued that the large-scale horizontal wind shears accompanying the regions of cyclonic motion within a PW can lead to significant plasma accumulation which acts as complimentary to the vertical wind shear process so that dense $E_{s}$ can form more efficiently and frequently. Note that at $E$ region altitudes the ion-neutral collision frequency is greater than the ion gyrofrequency, so the ion velocity is given by:

$\mathbf{V}_{i}=\mathbf{U}+\frac{e}{m_{i} v_{i}} \mathbf{E}+\beta_{i}(\mathbf{U} \times \mathbf{b})-D_{i} \frac{\nabla N}{N}$,

where $\Omega_{i}$ is the ion gyrofrequency, $v_{i}$ is the ion-neutral collision frequency, $\beta_{i}=\Omega_{i} / v_{i}, \mathbf{b}=\mathbf{B} /|\mathbf{B}|$ is the geomagnetic unit vector, $\mathbf{U}$ is the neutral wind velocity, $\mathbf{E}$ is the total electric field, $N$ is the plasma density, $D_{i}=k_{B} T_{i} / m_{i} v_{i}$ is the ion diffusion coefficient, $m_{i}$ and $T_{i}$ are the ion mass and ion temperature, and $k_{B}$ is Boltzmann's constant. In the $E$ region between 95 and $120 \mathrm{~km}$, the ions tend to move with $\mathbf{U}$ but also be subject to a Lorentz force that may deflect them away from the neutral wind velocity; since the direction of the geomagnetic field remains fixed, the sense of deflection depends of the direction of the neutral wind. As for the electrons, because the ratio $\beta_{e}=\Omega_{e} / v_{e}$ is very large, they are not affected by the neutral wind, therefore they simply follow the ions to neutralise the space charge.

In this process the plasma will converge only in horizontal areas of cyclonic motion where the wind flows counterclockwise. Figure 11 shows how plasma accumulates and converges in regions of cyclonic winds of a propagating PW. The situation is analogous to the classic wind-shear mechanism of $E_{s}$ formation but with the geometry now being in the horizontal rather than the vertical plane. Differences between the two processes, however, arise because of different characteristic scales involved, both in time and space. In fact, it is precisely these large characteristic scales that play the key role in the PW plasma accumulation process because they help reduce plasma diffusion (for details see Shalimov et al., 1999). It is important to stress that PW accumulation of ions does not necessarily lead to the formation of a strong $E_{S}$, which requires a vertical wind shear to be active, but certainly favours it. On the other hand, at adjacent areas of anticyclonic motions the ions move outwards, therefore making those areas less favourable for strong $E_{S}$ generation. As a result, for a westward propagating $\mathrm{PW}$, an ionosonde will detect intervals of high, followed by intervals of low, $E_{s}$ occurrence with a period equal to the PW period, that is, in the same fashion as illustrated in Fig. 5 for the CADI data.

In a different approach, it can be hypothesised that the passage of a PW and its interaction with the ions in the lower ionosphere can possibly affect the driving

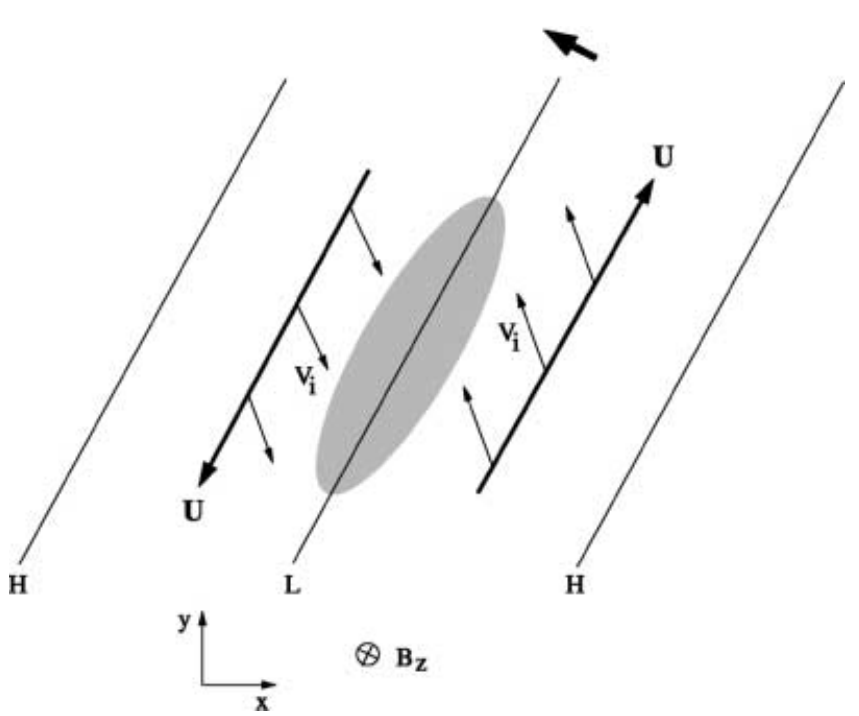

Fig. 11. Plasma convergence and accumulation of metallic ions over large areas occupied by horizontal wind shears produced by cyclonic winds in a westward propagating planetary wave. This applies for lower $E$ region altitudes where ion motion is controlled by the neutrals and the geomagnetic Lorentz force, thus ions are deflected inwards and, since they have long life times, tend to accumulate. Apparently, inside these areas it is easier to form strong sporadic $E$ layers (from Shalimov et al., 1999) 
terms in the instability process, in particular the electric field and the neutral wind. This notion was applied by Tsunoda et al. (1998) in an effort to explain a pronounced 5-day periodicity in the occurrence of the quasi-periodic (QP) echoes in midlatitude backscatter (e.g. see Yamamoto et al., 1992). They proposed that the occurrence of QP echoes is affected by a contribution of the wind to the dynamo electric field any by the changing direction of the neutral wind. To support their postulation that $\mathrm{PW}$ induced variations in $E$ region neutral wind can produce corresponding variations in the dynamo electric field, they relied on model results by Ito et al. (1986) on the dynamo effect of a quasi-2 day planetary wave. According to Tsunoda et al. (1998), a dynamo field could be generated by a PW if the $E$ region conductivity is comparable to or greater than that in the $F$ region and if the $\mathrm{PW}$ vertical wavelength is greater than the thickness of the $E$ region. Under these conditions, they argued that because the wind vector of the PW is elliptically polarised at midlatitudes, a preferred wind direction conductive to the generation of QP echoes through dynamo fields may occur every 5 days, thus imposing a strong 5-day modulation in echo occurrence.

Finally, a modulation in the ambient neutral wind by a PW can, in principle, have also a direct effect on the unstable state of the midlatitude $E$ region plasma and therefore to the backscatter occurrence. Because of the rather small ambient electric fields at midlatitude, recent studies suggested that the neutral wind, which is often ignored in theoretical calculations, might be of importance in the generation of plasma irregularities by the gradient drift instability (Kagan and Kelley, 1998). When considering the neutral wind as well, the linear dispersion relationship for the angular frequency and growth rate, for waves propagating perpendicular to the magnetic field, are:

$\omega=\frac{\mathbf{k} \cdot\left(\mathbf{V}_{e}+\psi_{0} \mathbf{V}_{i}\right)}{1+\psi_{0}}$

and

$$
\begin{aligned}
\gamma= & \frac{\psi_{0}}{\left(1+\psi_{0}\right) v_{i}}\left[\frac{\left[\mathbf{k} \cdot\left(\mathbf{V}_{e}-\mathbf{V}_{i}\right)\right]^{2}}{\left(1+\psi_{0}\right)^{2}}-k^{2} C_{s}^{2}\right] \\
& +\frac{\mathbf{k} \cdot\left(\mathbf{V}_{e}-\mathbf{V}_{i}\right)}{\left(1+\psi_{0}\right)^{2}} \cdot \frac{v_{i}}{\Omega_{i} L_{\perp} k} .
\end{aligned}
$$

In these equations, $k$ is the plasma wave number, $\psi_{0}=v_{e} v_{i} / \Omega_{i} \Omega_{e}, C_{s}$ is the acoustic speed, $\mathbf{V}_{e}$ and $\mathbf{V}_{i}$ are the electron and ion drift velocities, and $L_{\perp}=N /(d N /$ $d z \cos I)$ is the scale length of the plasma density gradient perpendicular to the magnetic field, where the symbols $N, I$ and $z$ designate the ambient plasma density, the magnetic dip angle, and the vertical direction, respectively.

Note that, besides the usual driving terms, that is, the ambient electric field entering via the electron drift velocity $\mathbf{V}_{e}=\mathbf{E} \times \mathbf{B} / B^{2}$ and the vertical density gradient $d N / d z$ provided by a sporadic $E$ layer, the neutral wind $\mathbf{U}$ is also included in the dispersion relation through the ion drift. The ion velocity, $\mathbf{V}_{i}$, is approximately equal to $\mathbf{U}$, since in the $E$ region the motion of the unmagnetised ions is controlled by collisions with the neutrals. It is important to stress that, because the driving density gradients perpendicular to $\mathbf{B}$ are lying in the meridional plane, this mechanism is most effective in generating large-scale primary irregularities propagating in the zonal direction because the theory requires the electric field to be parallel to the density gradient for plasma destabilisation. In this geometry, the ambient neutral wind is expected to contribute positively (negatively) to the instability if it has a sizeable zonal component that is antiparallel (parallel) to the $\mathbf{E} \times \mathbf{B}$ electron drift. Also note that, in this scenario, radars beaming northward observe short-scale irregularities generated, presumably, through nonlinear processes that cascade wave energy from the larger scale zonal primaries to shorter scale secondary waves propagating in other directions (e.g., Sudan, 1983).

In the context of the present study, the possibility exists for the PW wind field to alter decisively the ambient neutral wind so that the relative electron-ion drift $\mathbf{V}_{e}-\mathbf{V}_{i}$ to be modulated accordingly and drive the instability at an oscillatory manner in phase with the PW period. In this process, and in line with the previous discussion, the PW zonal component is expected to be much more important than the meridional one because it complies with the optimal geometry for instability and thus for the generation of plasma turbulence.

If the latter mechanism operates effectively, then it could explain the appearance and disappearance of echoes with periods comparable to those of planetary waves. However, there is a fact which casts doubt on the effectiveness of this process, that is, the rather small wind amplitudes associated with PW which are in the range of 10 to $30 \mathrm{~m} / \mathrm{s}$. Although these are somewhat comparable to the mean dynamo electric fields at midlatitude, they are well below the wind field variations associated, for example, with diurnal and semidiurnal tides (e.g. Meek et al., 1996) as well as large zonal wind shears associated with gravity waves (e.g. Larsen et al., 1998 and references therein). Also the $\mathrm{PW}$-induced ion drifts $\mathbf{V}_{i}$ are much smaller compared to $\mathbf{E} \times \mathbf{B}$ electron drifts caused by enhanced polarization electric fields which are supposed to occur locally during midlatitude backscatter conditions (e.g. Haldoupis et al., 1997; Shalimov et al., 1998).

\section{Summary and concluding comments}

We have provided more necessary details and new additional data analysis in order to supplement and extend recent work summarised in a geophysical research letter by Voiculescu et al. (1999). In brief, we have analysed a large database of midlatitude $50 \mathrm{MHz}$ backscatter, observed with the Sporadic $E$ Scatter Experiment (SESCAT) from Crete, Greece over four summers of continuous operation, to study the long-term variability in echo occurrence. Dominant periodicities 
with characteristic periods in the bands from 2 to 3 and 4 to 7 days are found to occur regularly, with no relation to geomagnetic activity. In addition, by analysing simultaneous digital ionosonde data from the same ionospheric volume, that were available only for one summer, we found that the same long-term periodicities also exist in the occurrence of strong sporadic $E$ layers.

These periodicities were attributed to travelling planetary waves, which are known to exist in the midlatitude mesosphere and lower thermosphere. Relying on results published in the open literature, we inferred that the characteristics of the long-term periodicities in $50 \mathrm{MHz}$ coherent echo and strong $E_{s}$ occurrence, that is, the prevailing periods and how they change with time during summer, the duration of the dominant periodicities, and the overall seasonal dependence, all compared well with corresponding planetary wave properties. To test this inference further, we have attempted for first time a direct comparison between the periodicities in our data and in simultaneous neutral wind observations at upper mesospheric heights made from central Germany. By applying the same method of dynamic spectral analysis in both data sequences, simultaneous spectrograms showed a good deal of agreement between the planetary wave periods and those seen simultaneously in the occurrences of strong $E_{s}$ and $50 \mathrm{MHz}$ backscatter.

The results presented, although not fully conclusive, are certainly supportive of the postulation of a planetary wave link with nighttime $E$ region phenomena detected by ionosondes and coherent backscatter radars. Since the presence of a strong $E_{s}$ is known to be a necessary prerequisite for coherent backscatter to occur at midlatitudes, the most important and challenging implication of our findings is about the potential role that planetary waves play in $E_{s}$ formation. This option opens a new dimension in the ongoing research into sporadic $E$ layering phenomena in the ionosphere and demands new theoretical and observational work. The first effort to formulate the planetary wave role in midlatitude $E_{s}$ production was made recently by Shalimov et al. (1999), who suggested a simplified theoretical model based on the ionconverging properties of large-scale horizontal wind shears in the zonal wind which accompany regions of positive vorticity within a planetary wave propagating westward in the Northern Hemisphere. A detailed discussion of this mechanism in relation to our observations was provided here. The observed close relation between the long-term periodicities in $E_{s}$ occurrence and those in the zonal wind component of the planetary wave data is maybe the first direct hint in support of the Shalimov et al. (1999) mechanism. We need to stress however, this is merely a tentative indication and more analysis in depth is needed for this mechanism to be verified, a task worth undertaking in a future study. In addition, this mechanism needs further theoretical development to include time varying and vertical wind, effects on local convergence and divergence of the plasma.
Acknowledgements. We are grateful to C. Jacobi, University of Leipzig, for his kindness in making available the Collm data used in our analysis. One author (M.V) thanks University of Crete for providing support during her three month stay at the Ionospheric Physics Laboratory of the Physics Department, where part of the work was completed. Another author (S.S) thanks the Greek Ministry of National Economy, Directorate on International Economic Organisations, for supporting his University of Crete visit through a two-month fellowship. SESCAT and CADI were operated by the University of Crete and Max-Planck-Institut fur Aeronomie.

Topical Editor M. Lester thanks A. Bourdillon and another referee for their help in evaluating this paper.

\section{References}

Apostolov, E. M., D. Altadill, and L. Alberta, Characteristics of quasi-2-day oscillations in the $f_{0} \mathrm{~F} 2$ at northern middle latitudes, J. Geophys. Res., 100, 12 163, 1995.

Charney, J. G., and P. G. Drazin, Propagation of planetary-scale disturbances from the lower into the upper atmosphere, J. Geophys. Res., 66, 83, 1961.

Chen, P.-R., Two-day oscillations of the equatorial ionization anomaly, J. Geophys. Res., 97, 6343, 1992.

Clark, R. R., A. C. Current, A. H. Manson, C. E. Meek, S. K. Avery, S. E. Palo, and T. Aso, Hemispheric properties over two day wave from mesosphere lower thermosphere radar observations, J. Atmos. Terr. Phys., 56, 1279, 1994.

Deng, W. et al., Coordinated global radar observations of tidal and planetary waves in the mesosphere and lower thermosphere during 20-30 January 1993, J. Geophys. Res., 102, 7307, 1997.

Forbes, J. M., Planetary waves in the thermosphere-ionosphere system, J. Geomag. Geoelectr., 48, 91, 1996.

Forbes, J. M., Tidal and planetary waves, in The upper mesosphere and lower thermosphere, a review of experiment and theory, eds. R. M. Johnson, and T. L. Killeen, p. 67, 1994.

Fraser, G. J., The 5-day wave and ionospheric absorption, J. Atmos. Terr. Phys., 39, 12, 1977.

Geisler, J. E., and R. E. Dickinson, The five-day wave on a sphere with realistic zonal winds, J. Atmos. Sci., 33, 632, 1976.

Haldoupis, C., and K. Schlegel, A $50 \mathrm{MHz}$ radio Doppler experiment for mid-latitude $E$-region coherent backscatter studies. System description and first results, Radio Sci., 28, 959, 1993.

Haldoupis, C., and K. Schlegel, Characteristics of midlatitude coherent backscatter from ionospheric $E$ region obtained with Sporadic E Scatter experiment, J. Geophys. Res., 101, 13 387, 1996.

Haldoupis, C., D. T. Farley, and K. Schlegel, Type 1 echoes in the midlatitude E region, Ann. Geophysicae, 15, 908, 1997.

Harris, T. J., A long-term study of the quasi-two-day wave in the middle atmosphere, J. Atmos. Terr. Phys., 56, 569, 1994.

Holton, J. R., An introduction to dynamic meteorology, Academic Press, New York, 1982.

Hussey, G. C., K. Schlegel, and C. Haldoupis, Simultaneous $50 \mathrm{MHz}$ coherent backscatter and digital observations in the midlatitude $E$ region, J. Geophys. Res., 103, 6991, 1998.

Hysell, D. L., and J. D. Burcham, $30 \mathrm{MHz}$ radar interferometer observations of midlatitude $E$ region irregularities, J. Geophys. Res., 105, 12 797, 2000.

Ito, R., K. Susumu, and T. Tsuda, Consideration of an ionospheric wind dynamo driven by a planetary wave with a two-day period, J. Atmos. Terr. Phys., 48, 1, 1986.

Jacobi, C., R. Schminder, and D. Kürschner, Planetary wave activity obtained from long-period (2-18 days) variations of mesopause regions over Central Europe $\left(52^{\circ} \mathrm{N}, 15^{\circ} \mathrm{E}\right), \mathrm{J}$. Atmos. Sol.-Terr. Phys., 60, 81, 1998.

Kagan, L. M., and M. C. Kelley, A wind-driven gradient drift mechanism for mid-latitude $E$ region ionospheric irregularities, Geophys. Res. Lett., 25, 4141, 1998.

Larsen, M. F., S. Fukao, M. Yamamoto, R. Tsunoda, K. Igarashi, and T. Ono, The SEEK chemical release experiment: Observed 
neutral wind profile in a region of sporadic E, Geophys. Res. Lett., 25, 1789, 1998

Laštovicka, J., V. Fišer, and D. Pancheva, Long-term trends in planetary wave activity (2-15 days) at $80-100 \mathrm{~km}$ inferred from radio wave absorption, J. Atmos. Terr. Phys., 56, 893, 1994

Manson, A. H., C. E. Meek, J. L. Fellous, and M. Massbeuf, Winds oscillations ( $\sim 6 \mathrm{~h}-6$ days) in the upper-middle atmosphere at Montpazier (France, $45^{\circ} \mathrm{N}, 1^{\circ} \mathrm{E}$ ) and Saskatoon (Canada, $52^{\circ} \mathrm{N}, 107^{\circ} \mathrm{W}$ ), in 1979-1980, J. Atmos. Terr. Phys., 49, 1059, 1987.

Meek, C. E., A. H. Manson, S. J. Franke, W. Singer, P. Hoffmann, R. R. Clark, T. Tsuda, T. Nakamura, M. Tsutsumi, M. Hagan, D. C. Fritts, J. Isler, and Y. I. Portnyagin, Global study of Northern Hemisphere quasi 2-day wave events in recent summers near $90 \mathrm{~km}$ altitude, J. Atmos. Terr. Phys., 58, 1401, 1996.

Müller, H. G., and L. Nelson, A travelling quasi 2-day wave in the meteor region, J. Atmos. Terr. Phys., 40, 761, 1978.

Pancheva, D., L. F. Alberta, and B. A. de la Morena, Simultaneous observation of the quasi-two-day variations in the lower and upper ionosphere over Europe, J. Atmos. Terr. Phys., 56, 43, 1994.

Pancheva, D., J. Laštovicka, and B. A. de la Morena, Quasiperiodic fluctuations in ionospheric absorption in relation to planetary activity in the stratosphere, J. Atmos. Terr. Phys., 53, $1151,1991$.

Raghava Reddi, C., and G. Ramkumar, Long period wind oscillations in the meteor region over Trivandarum $\left(8^{\circ} \mathrm{N}, 77^{\circ} \mathrm{E}\right)$, J. Atmos. Terr. Phys., 57, 1, 1995.

Riggin, D., W. E. Swartz, J. Providakes and D. T. Farley, Radar studies of long-wavelength waves associated with midlatitude sporadic E layers, J. Geophys. Res., 91, 8011, 1986.

Rogers, C. D., and A. Prata, Evidence for a travelling 2-day wave in the middle atmosphere, J. Geophys. Res., 86, 9661, 1981.

Salby, M. L., Survey of planetary scale travelling waves: the state of theory and observations, Rev. Geophys. Space Phys., 22, 209, 1984.

Salby, M. L., The 2-day wave in the middle atmosphere: observations and theory, J. Geophys. Res., 86, 9654, 1981.

Shalimov, S., C. Haldoupis, M. Voiculescu, and K. Schlegel, Midlatitude $E$ region plasma accumulation driven by planetary wave horizontal wind shears, J. Geophys. Res., 104, 28207 , 1999.

Shalimov, S., C. Haldoupis, and K. Schlegel, Large polarization electric fields associated with midlatitude sporadic E, J. Geophys. Res., 103, 11 617, 1998.
Sprenger, K., Diurnal and seasonal variations of occurrence of sporadic E-layers over Central Europe, Gerlands Beit. Geophys., 90, 305, 1981 .

Sudan, R. N., Unified theory of type I and type II irregularities in the equatorial electrojet, J. Geophys. Res., 88, 4853, 1983.

Tanaka, T., and S. V. Venkateswaran, Characteristics of fieldaligned $E$-region irregularities over Iioka $\left(36^{\circ}\right)$, Japan-I, J. Atmos. Terr. Phys., 44, 381, 1982.

Tsunoda, R. T., M. Yamamoto, K. Igarashi, K. Hocke, and S. Fukao, Quasi-periodic radar echoes from midlatitude sporadic $E$ and role of the 5-day planetary wave, Geophys. Res. Lett., 7, 951, 1998.

Vincent, R. A., Planetary and gravity waves in the mesosphere and lower thermosphere, Adv. Space Res., 10(12), 93, 1990.

Voiculescu, M., C. Haldoupis, and K. Schlegel, Evidence for planetary wave effects on midlatitude backscatter and sporadic E layer occurrence, Geophys. Res. Lett., 26, 1105, 1999.

Volland, H., Atmospheric tidal and planetary waves, Kluwer Boston, MA, 1988.

Ward, W. E., D. Y. Wang, B. H. Solheim, and G. G. Shepherd, Observations of the two-day wave in WINDII data during January 1993, Geophys. Res. Lett., 23, 2923, 1996.

Whitehead, J. D., Recent work on mid-latitude and equatorial sporadic-E, J. Atmos. Terr. Phys., 51, 401, 1989.

Williams, C. R., and S. K. Avery, Analysis of long period waves using the MST radar at Poker Flat, Alaska, J. Geophys. Res., 97, 20855,1992

Wu, D. L., P. B. Hay, W. R. Skinner, A. R. Marshall, M. D. Burrage, R. S. Leiberman, and D. A. Ortland, Observations of the quasi 2-day wave from high resolution Doppler imager in UARS/MLS temperature measurements, Geophys. Res. Lett., 24, 2853, 1993.

Wu, D. L., E. F. Fishbein, W. G. Read, and J. W. Waters, Excitations and evolution of the quasi 2-day wave observed in UARS/MLS temperature measurements, J. Atmos. Sci., 53, 728, 1996

Wu, D. L., P. B. Hays, and W. R. Skinner, Observations of the fiveday wave in the mesosphere and lower thermosphere, Geophys. Res. Lett., 21, $2733,1994$.

Yamamoto, M., S. Fukao, T. Ogawa, T. Tsuda, and S. Kato, A morphological study on midlatitude $E$ region field aligned irregularities observed with MU radar, J. Atmos. Terr. Phys., 54, 769, 1992.

Zhou, Q. H., Two-day oscillation of electron concentration in the lower ionosphere, J. Atmos. Sol-Terr. Phys., 60, 1669, 1998. 